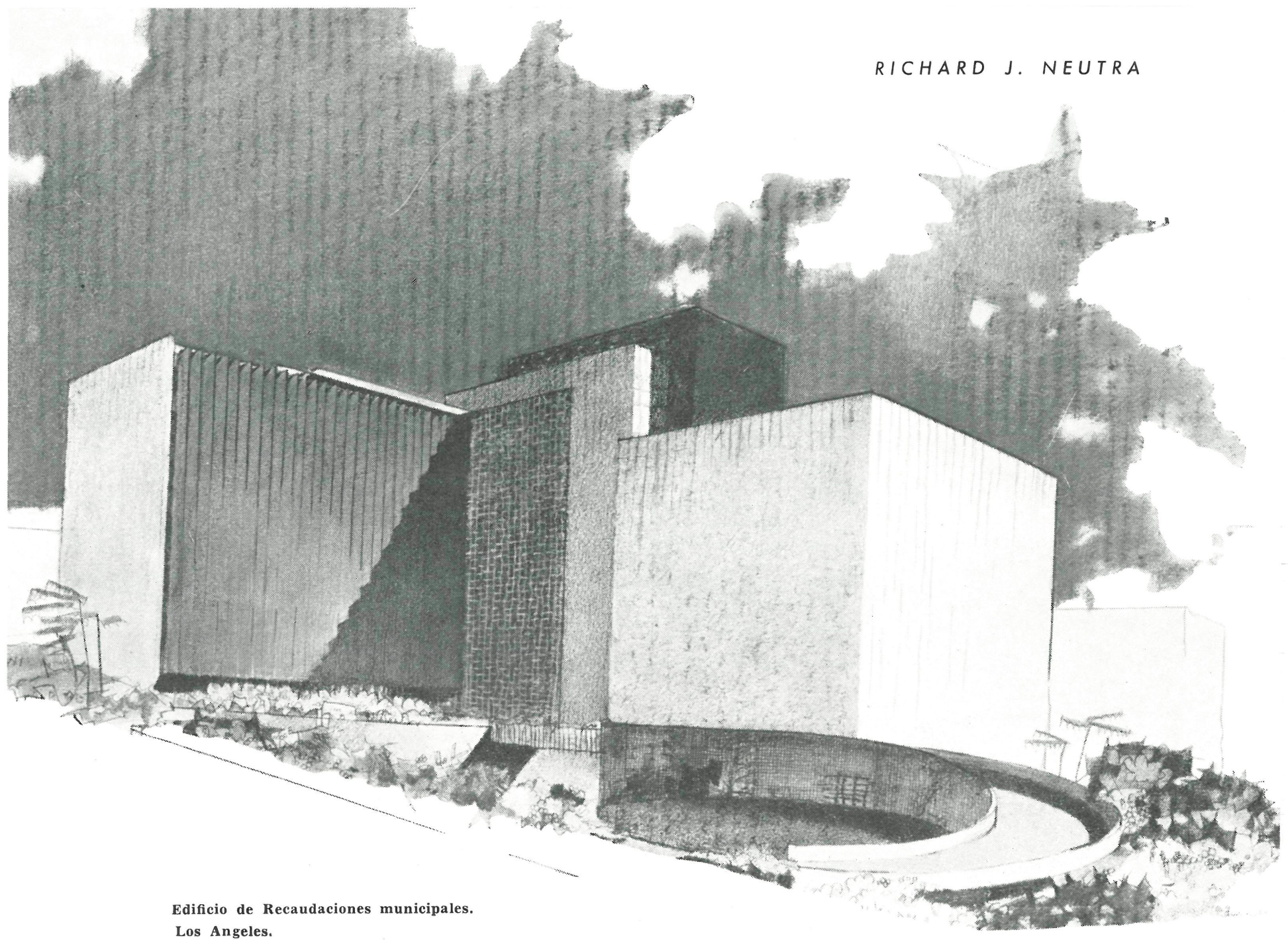

Los Angeles.

Debemos defender nuestras propias ideas del

$100-30$ mismo modo que defendemos firmemente a la propia esposa, frente a los elegantes flirteos.

\title{
tengamos ideas propias
}

Refiriéndome, hace algunos años, a la Embajada de los Estados Unidos en Karachi, explicaba el proyecto al Comité. Su presidente, un caballero muy culto y arquitecto de prestigio, después de escuchar y observar cómo había yo razonado la colocación de quitasoles metálicos y móviles en un ala de la Embajada y en su parte frontal, dijo a título de amigable comentario: “¿No piensa usted, señor Neutra, que esas persianas móviles son un tanto anticuadas para un proyecto de hoy?"

Quedé desconcertado unos segundos; luego respondí: "Voy a contarles una pequeña historieta, señores: Graham Bell-y, según propala la U. R. S. S., algún otro en el interior de Rusia-fué el inventor del teléfono. En cierta época fué una novedad. Durante largo tiempo había desarrollado la idea de la producción y aceptación para su joven talento destartalado. Al fin, parecía ir por buen camino. El tenía una casa en Wáshington D. C. e instaló un teléfono en ella. Mas poco después le decían algunos buenos amigos que el teléfono era, en efecto, una buena cosa, pero que se había hecho tan común que resultaba vulgar. ¿No ven ustedes? Bell vió pronto la solución: rompió su suscripción con la telefónica y volvió a las señales de humo." 


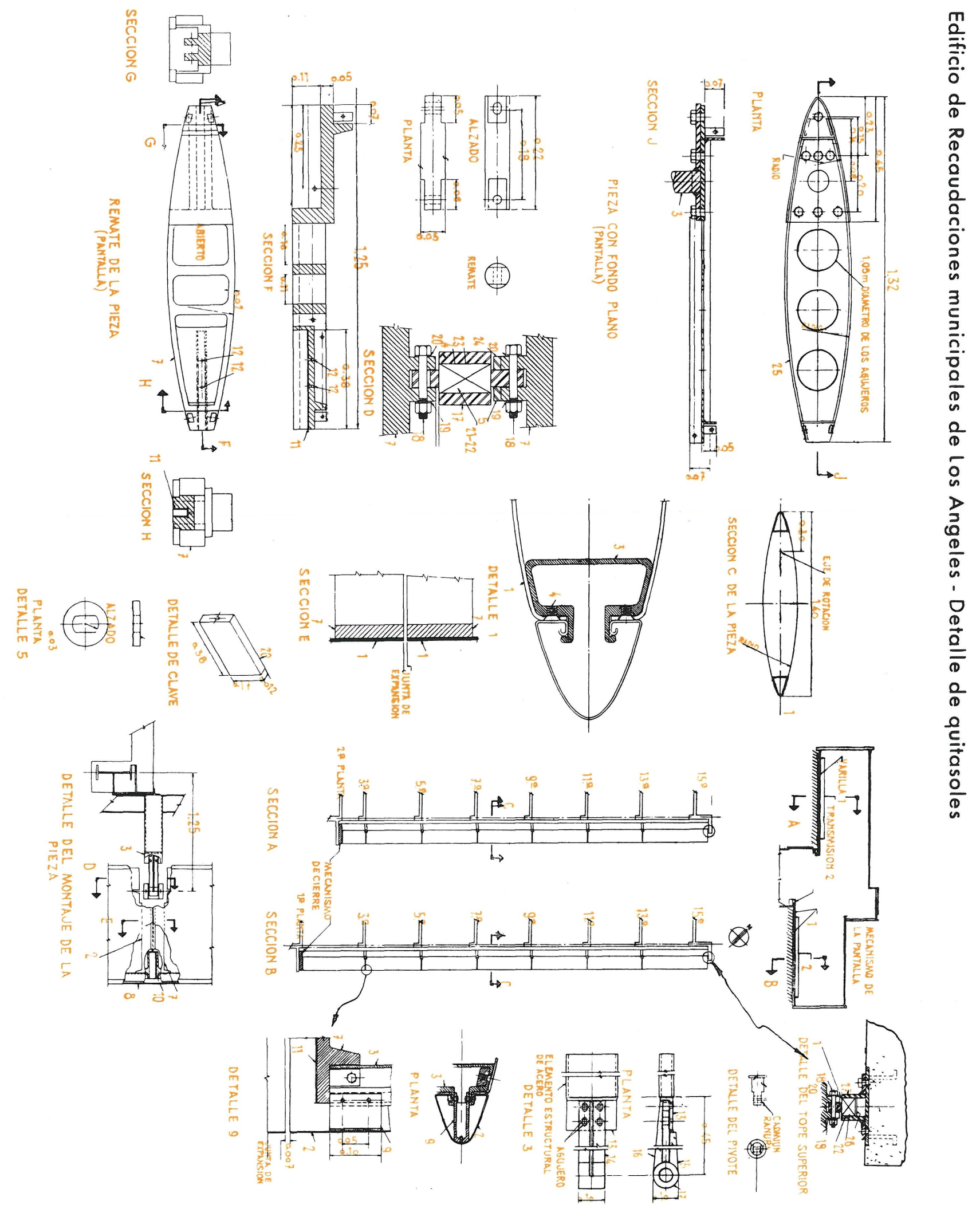



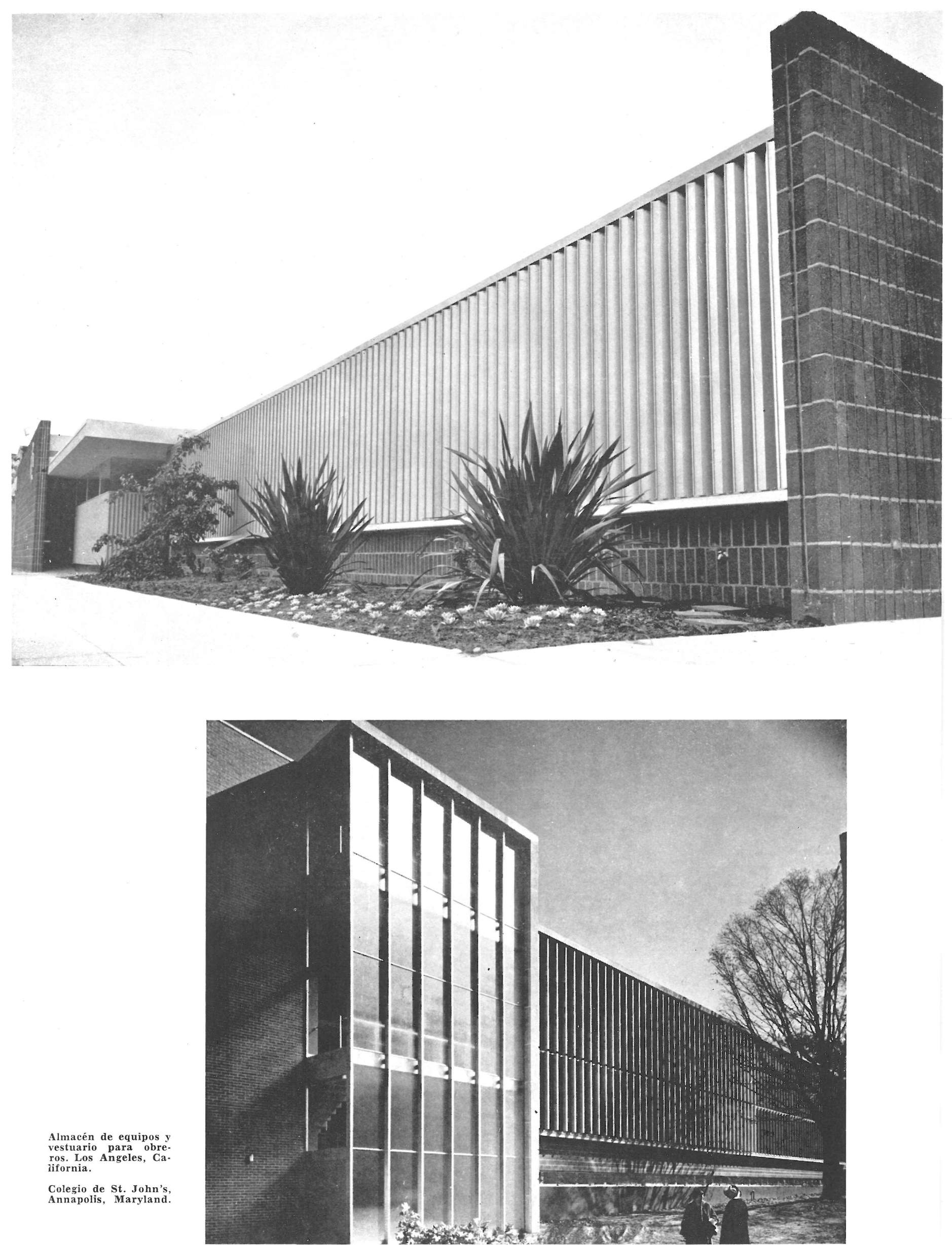

Almacén de equipos y vestuario para obre iifornia.

Colegio de St. John's, Annapolis, Maryland. 
Así, por una pequeña broma, me estaba permitido utilizar una idea de mi propiedad, aunque otros la habían encontrado también bastante buena para utilizarla ampliamente después que yo obtuve pequeños éxitos con ella. Yo había usado y desarrollado largamente la idea de que el movimiento del sol sobre la tierra no exigía fijeza, sino igualmente movilidad de quitasoles e inventos reguladores del calor, y no las persianas o brise-soleil fijos, franceses, brasileños o persas, que aunque maravillosos inventos con largo historial no podrían quizás dar satisfacción completa.

Así, hace muchos años, antes de la tormenta provocada por la casa en el desierto, yo empecé con persianas a base de láminas metálicas regulables a mano $y$, finalmente, a base de metales ligeros, controlados electrónicamente.

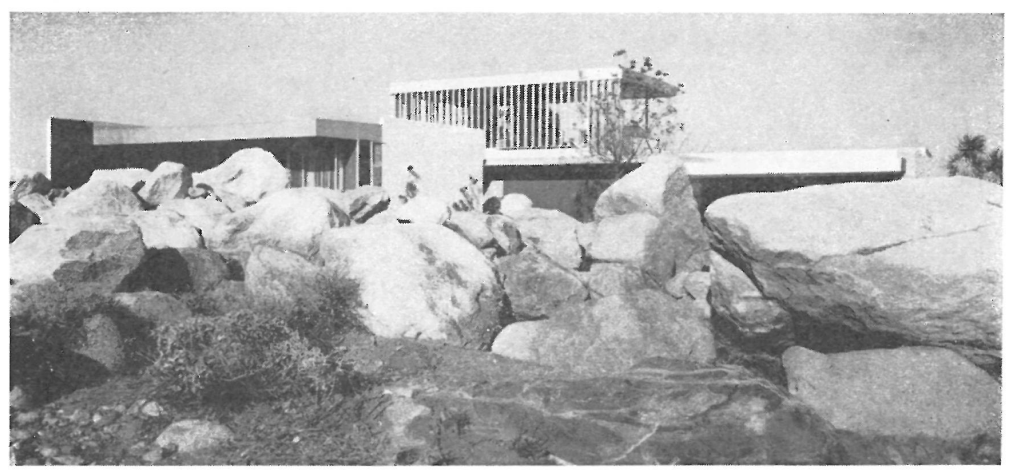

Quitasoles en la Residencia Edgar Kaufmann.

Palm Springs. California.

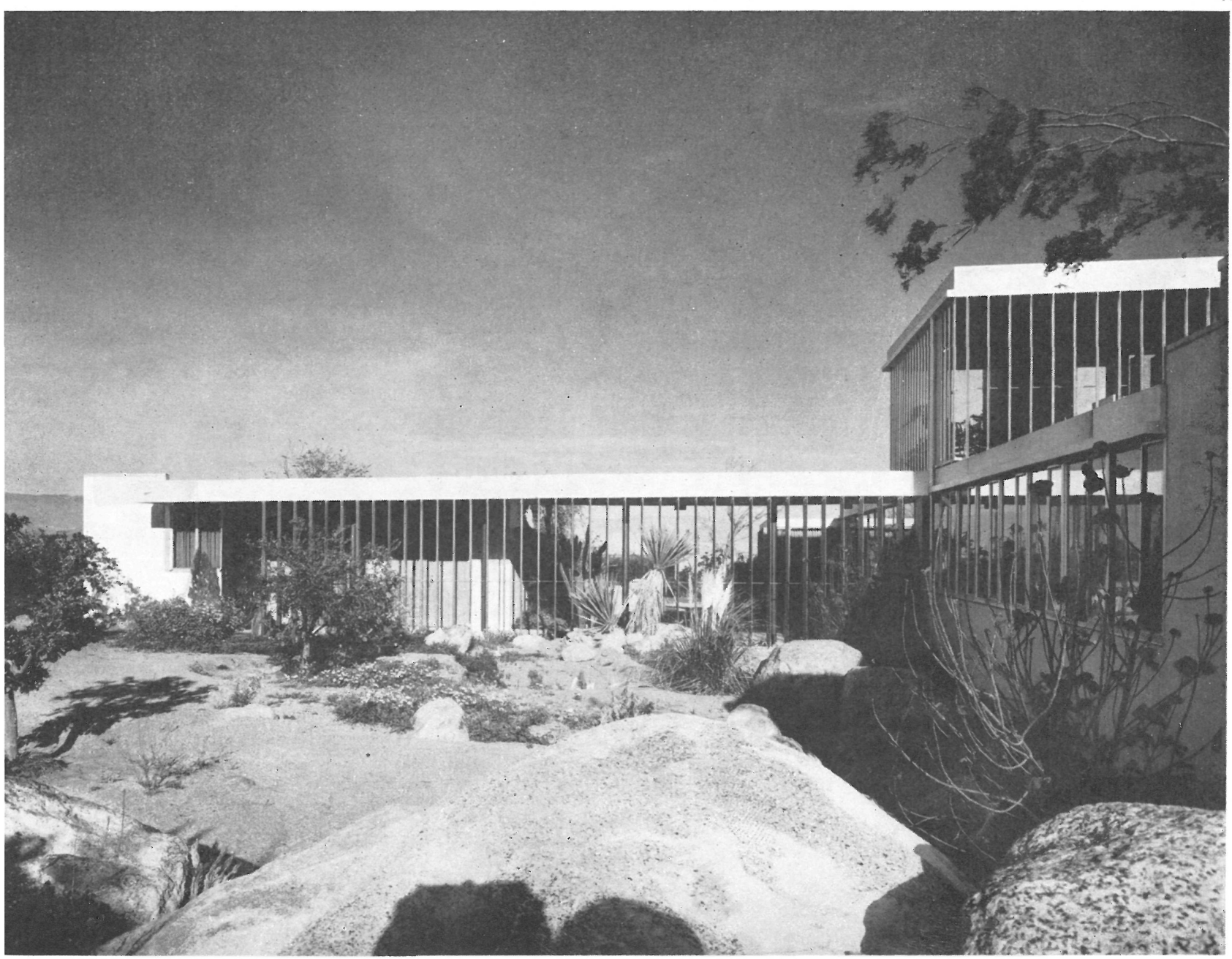




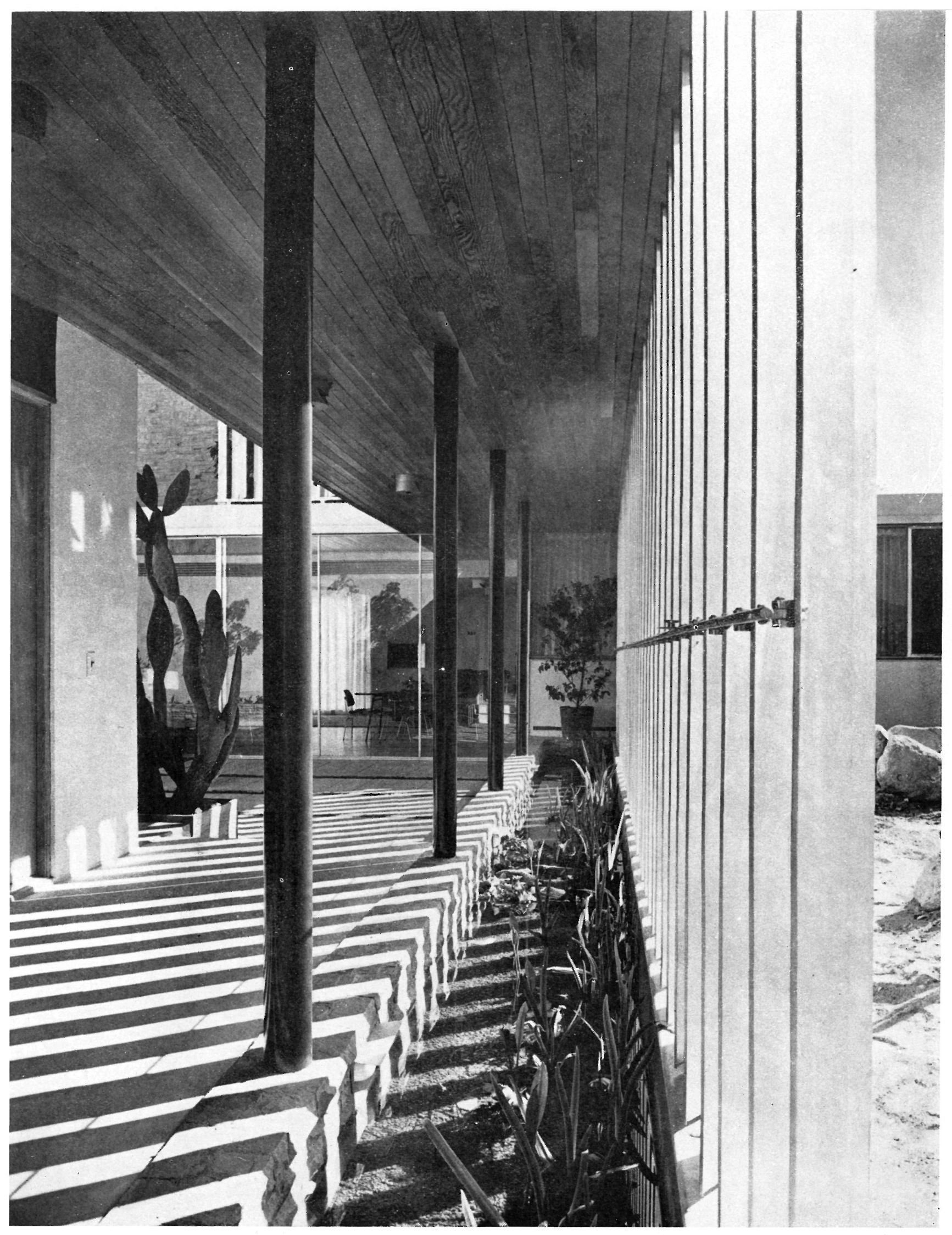




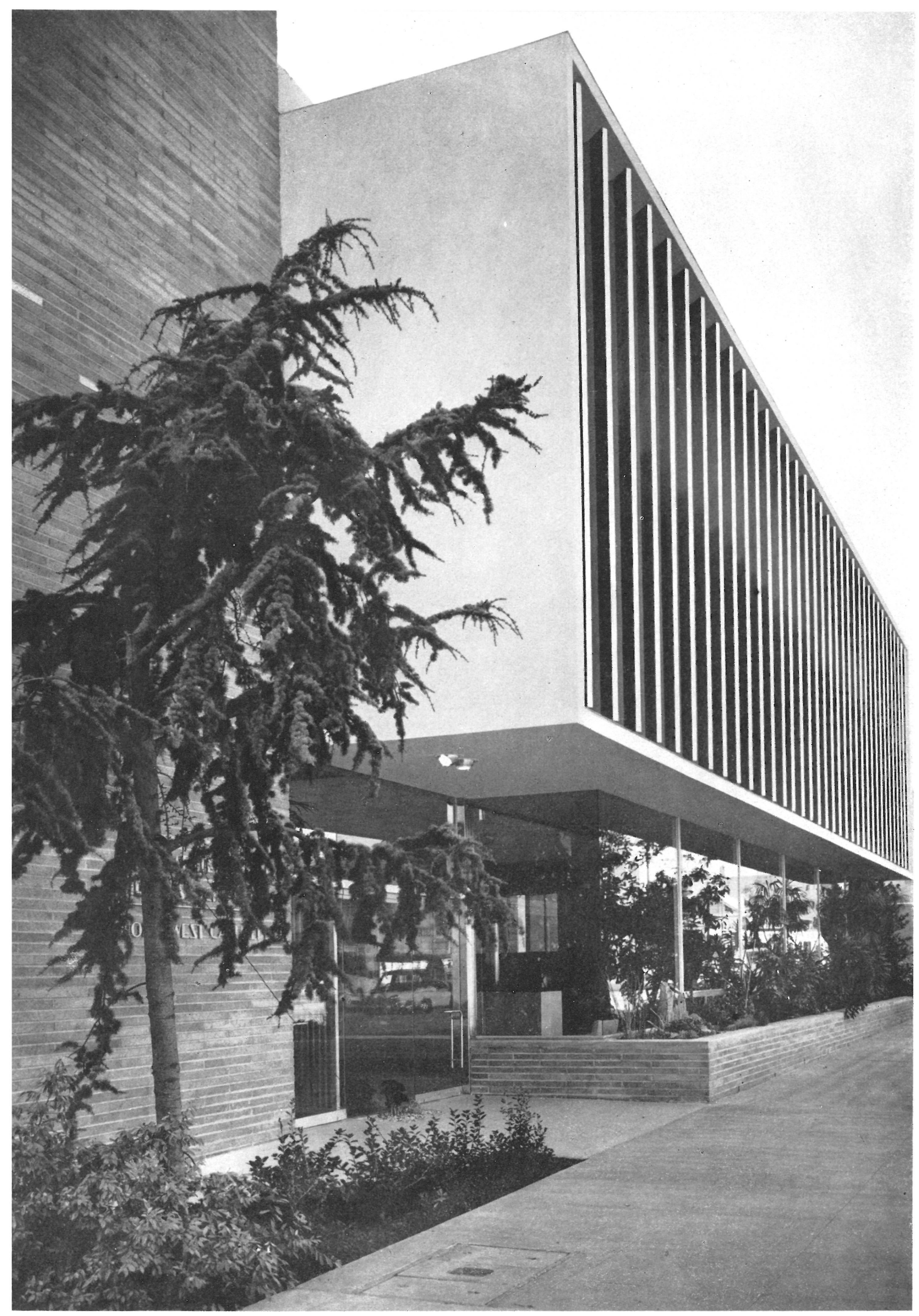




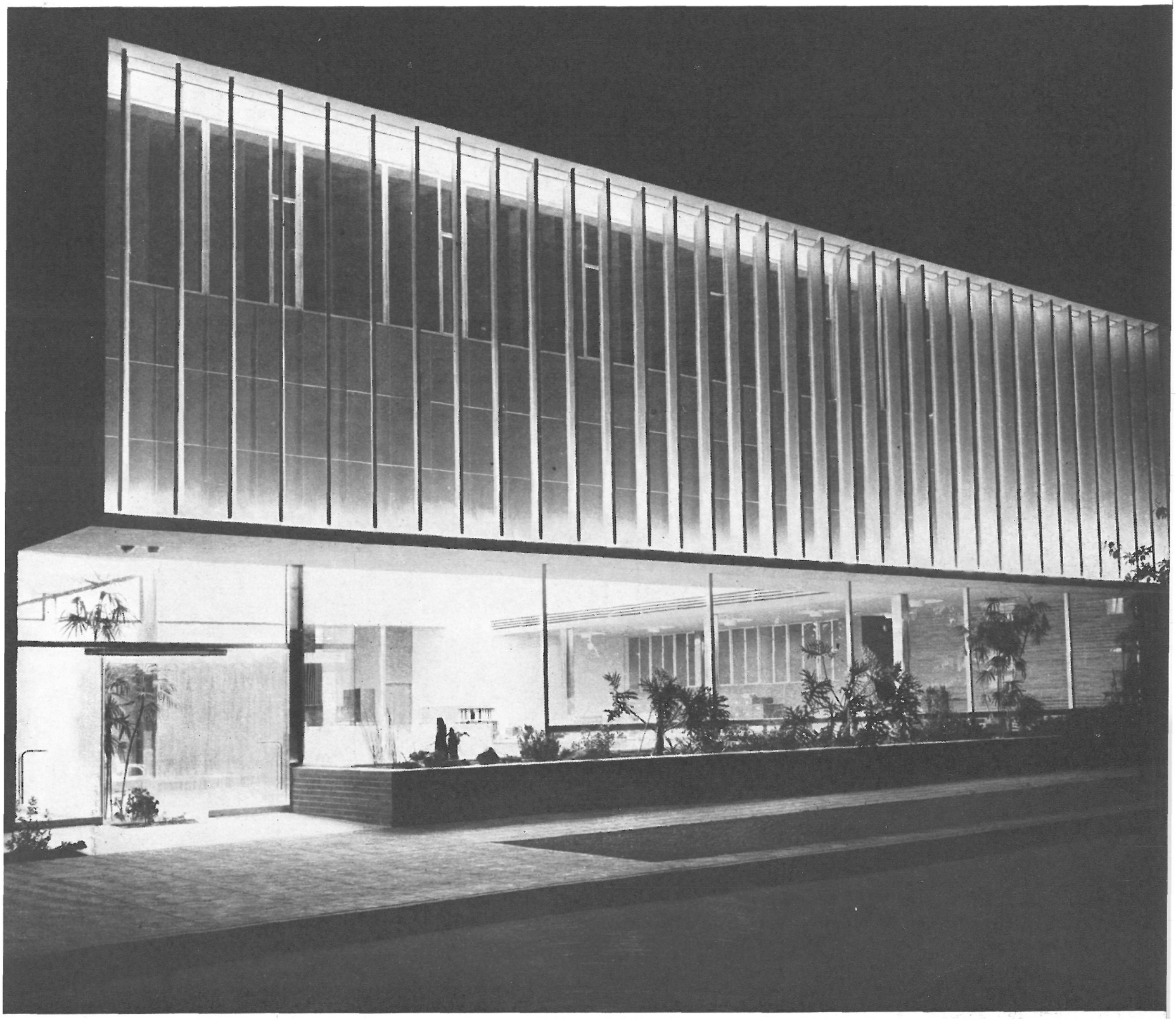

Compañía Mutua de Seguros del Noroeste. Los Angeles, California.

En el Registro de Los Angeles "Memorias de una ciudad", o caja de limaduras de un condado-como lo llama mi colaborador-, estas persianas se han convertido en colosales e intrincadas instalaciones cuyos elementos alcanzan centenares de pies de altura.

Pero durante mi progreso intermedio, por ejemplo, un edificio para una compañía de seguros, no sólo ganó cuatro premios nacionales de confort, sino que buscó y consiguió que se hicieran otros edificios semejantes, igualmente con quitasoles. Fué la "gran moda", y pronto fabricantes especializados compraron las patentes y convirtieron el trabajo "de un modesto calderero" en gran industria, con perfeccionamiento de modelos, etcétera. Esto me ha pasado con media docena de inventos, y iasi debe ser! 
Ningún derecho de autor debe ser reclamado para el verdadero progreso y para los medios de uso contemporáneo, que se dirigen a hacer más "biológicamente soportable" esta vida civilizada desvariada y descompensada. En un bosque, desde luego, uno no necesita recibir la sombra de persianas regulables, activadas electrónicamente. Pero es un invento en las calles de nuestras ciudades, notoriamente cerradas por edificios de cristal, aun en las orientaciones más improbables e inútiles. El viejo Sol, todavía recorre su camino establecido, sobre indiferentes e ignoradas ciudades, desnudas de árboles y determinadas por pasados "valores económicos", de modo que la vitalidad debilitada y la pura supervivencia con vigor orgánico se hace dudosa e impracticable.

Trasladar hombres de noche es una cosa; tenerlos allí sobreviviendo es otra cosa muy diferente. Y así es, dilatando el punto de vista, el caso de una gran ciudad, densa, como Tokio, con sus nueve millones de habitantes, soportados de bueno o mal grado, y tener todavía el milagro de que prosiga la vida humana.

Esto es realmente nuestro, la asignación de los arquitectos proyectistas, y los resultados aparecen sólo parcialmente a la vista $\mathrm{y}$ puede que nunca sean completamente fotografiados.

La entidad orgánica hombre, mujer y niño no puede ser plasmada ni siquiera en los mejores libros ilustrados. Yo amo a mis colegas y a nuestra maravillosa profesión, que pueden salvar a la humanidad, aquí, allá y más allá de las fronteras y de las cortinas o telones políticos.

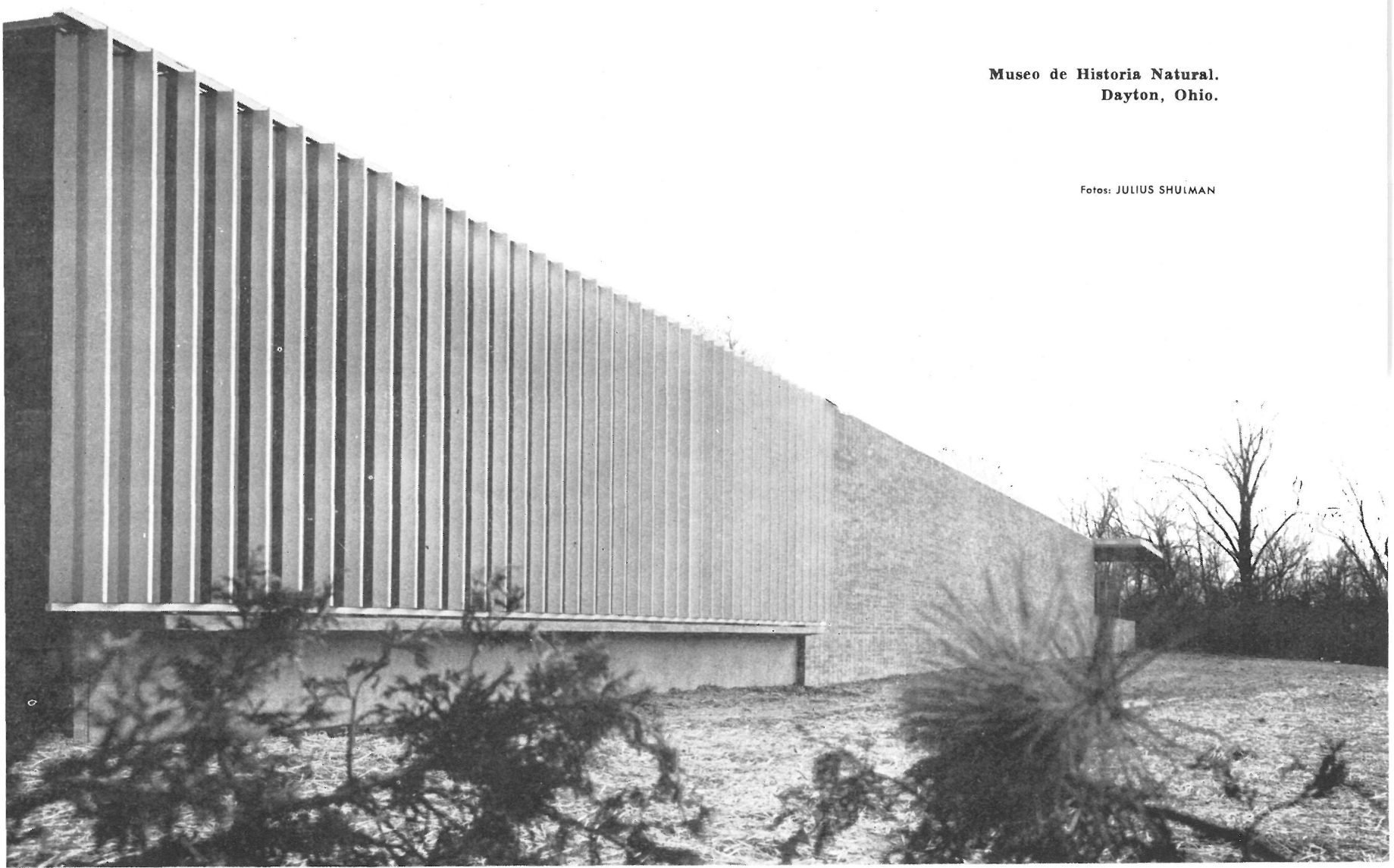

